\title{
$\alpha 7$ Nicotinic Receptor Promotes the Neuroprotective Functions of Astrocytes against Oxaliplatin Neurotoxicity
}

\author{
Lorenzo Di Cesare Mannelli, Barbara Tenci, Matteo Zanardelli, \\ Paola Failli, and Carla Ghelardini
}

Department of Neuroscience, Psychology, Drug Research and Child Health (NEUROFARBA), Pharmacology and Toxicology Section, University of Florence, 50139 Florence, Italy

Correspondence should be addressed to Lorenzo Di Cesare Mannelli; lorenzo.mannelli@unifi.it

Received 23 March 2015; Revised 19 May 2015; Accepted 20 May 2015

Academic Editor: Nicola Maggio

Copyright (C) 2015 Lorenzo Di Cesare Mannelli et al. This is an open access article distributed under the Creative Commons Attribution License, which permits unrestricted use, distribution, and reproduction in any medium, provided the original work is properly cited.

\begin{abstract}
Neuropathies are characterized by a complex response of the central nervous system to injuries. Glial cells are recruited to maintain neuronal homeostasis but dysregulated activation leads to pain signaling amplification and reduces the glial neuroprotective power. Recently, we highlighted the property of $\alpha 7$ nicotinic-acetylcholine-receptor (nAChR) agonists to relieve pain and induce neuroprotection simultaneously with a strong increase in astrocyte density. Aimed to study the role of $\alpha 7 \mathrm{nAChR}$ in the neuron-glia cross-talk, we treated primary rat neurons and astrocytes with the neurotoxic anticancer drug oxaliplatin evaluating the effect of the $\alpha 7$ nAChR agonist PNU-282987 (PNU). Oxaliplatin ( $1 \mu \mathrm{M}, 48 \mathrm{~h})$ reduced cell viability and increased caspase-3 activity of neuron monocultures without damaging astrocytes. In cocultures, astrocytes were not able to protect neurons by oxaliplatin even if glial cell metabolism was stimulated (pyruvate increase). On the contrary, the coculture incubation with $10 \mu \mathrm{M}$ PNU improved neuron viability and inhibited apoptosis. In the absence of astrocytes, the protection disappeared. Furthermore, PNU promoted the release of the anti-inflammatory cytokine TGF- $\beta 1$ and the expression of the glutamate-detoxifying enzyme glutamine synthetase. The $\alpha 7$ $\mathrm{nAChR}$ stimulation protects neurons from oxaliplatin toxicity through an astrocyte-mediated mechanism. $\alpha 7 \mathrm{nAChR}$ is suggested for recovering the homeostatic role of astrocytes.
\end{abstract}

\section{Introduction}

The development of painful neuropathies is a dose limiting side effect of commonly used chemotherapeutic agents, including platinum drugs [1-3]. Repeated oxaliplatin infusions induce grade $\geq 2$ neuropathy in $40-50 \%$ of patients receiving standard treatment regimens, with grade $\geq 3$ neuropathy in $10-20 \%$ of patients $[4,5]$. After a cumulative dose of $750-850 \mathrm{mg} / \mathrm{m}^{2} 82-93 \%$ of patients experience symptoms of neuropathy including $12-34 \%$ with grade $3 / 4$ neuropathy $[6,7]$.

The pathophysiological mechanisms of chemotherapy neurotoxicity are still little known. Several nervous cell alterations are involved in the final neuron damage [8], limiting the possibilities to develop effective therapies $[9,10]$. In a rat model of oxaliplatin neuropathy, we have highlighted the relationship between the peripheral nervous injuries (with the resulting aberrant somatosensory processing) and the activation of glial cells (microglia and astrocytes) in both spinal cord and supraspinal areas [11]. Glial activation, in particular astrocytes, is strictly related to oxaliplatindependent pain since glial inhibitors reduce mechanical and thermal hypersensitivity [12]. On the other hand, glial cells evoke neuroprotective mechanisms [13] and the block of glial-related signals impairs functional recovery after nerve injuries [14], suggesting that tout court glial inhibition may relieve pain but hinders the rescue mechanisms that protect nervous tissue from the damage triggering chronic pain. Recently, the stimulation of the $\alpha 7$ subtype of the nicotinic receptors ( $\alpha 7 \mathrm{nAChR}$; see $[15,16]$ for review) has emerged as effective in reducing oxaliplatin-dependent pain and preventing damage to the nervous tissue. These effects parallel 
with increased glial cell number in a region-specific manner [17]. $\alpha 7 \mathrm{nAChR}$ seems to be able to modulate glial cells distinguishing between the positive, protective component of microglia and astrocyte signaling and the pathological painful pathway. Nevertheless, the relevance of glial cells in the $\alpha 7 \mathrm{nAChR}$ signaling network as well as the molecular mechanisms remains unclear.

Aimed at improving the knowledge about the role of $\alpha 7$ $\mathrm{nAChR}$ in the neuron-glia signaling, primary neurons and astrocytes were cocultured in the presence of PNU-282987 (PNU), a selective and potent $\alpha 7 \mathrm{nAChR}$ agonist [18-20]. The protective component of $\alpha 7 \mathrm{nAChR}$ stimulation was focused using the anticancer drug oxaliplatin as neurotoxic agent. According to our research, oxaliplatin-induced alterations in nervous cell cultures represent a valuable in vitro model for studying cell damage mechanisms and screening novel protective molecules [21].

\section{Materials and Methods}

2.1. Cell Culture Preparation. Sprague-Dawley rats (Harlan, Varese, Italy) were used to obtain primary cell cultures. Animals were housed in CeSAL (Centro Stabulazione Animali da Laboratorio, University of Florence), in $26 \times 41 \mathrm{~cm}$ cage, were fed with standard laboratory diet and tap water ad libitum, and were kept at $23 \pm 1^{\circ} \mathrm{C}$ with a $12 \mathrm{~h}$ light/dark cycle, light at 7 a.m. All animal manipulations were carried out according to the European Community guidelines for animal care (DL 116/92, application of the European Communities Council Directive of November 24, 1986, 86/609/EEC). Formal approval to conduct the experiments described was obtained from the Animal Subjects Review Board of the University of Florence. The ethical policy of the University of Florence complies with the Guide for the Care and Use of Laboratory Animals of the US National Institutes of Health (NIH Publication number 85-23, revised 1996; University of Florence assurance number: A5278-01).

Primary cultures of astrocytes were obtained according to the method described by McCarthy and de Vellis [22]. Briefly, the cerebral cortex of newborn (P1-P3) SpragueDawley rats (Harlan, Padova, Italy) was dissociated in Hanks balanced salt solution containing $0.5 \%$ trypsin $/ 0.2 \%$ EDTA and $1 \%$ DNase (Sigma-Aldrich, Milan, Italy) for $30 \mathrm{~min}$ at $37^{\circ} \mathrm{C}$. The suspension was mechanically homogenized and filtered. Cells were plated in high-glucose DMEM with 20\% FBS (Life Technologies, Milan, Italy). Confluent primary glial cultures were used to isolate astrocytes, removing microglia and oligodendrocytes by shaking. After 21 days of culture, astrocytes were plated according to experimental requirements. Experiments were performed 21 days after cell isolation. GFAP-positive cells were 95-98\% [23].

Cortical neurons were isolated from rat embryos (embryonic days 14-16; Sprague-Dawley rats; Harlan, Padova, Italy). The cortex was dissociated in Hanks balanced salt solution containing $0.5 \%$ trypsin/0.2\% EDTA and $1 \%$ DNase for $10 \mathrm{~min}$ at $37^{\circ} \mathrm{C}$ under mild stirring. The suspension was mechanically homogenized and filtered. Cells were plated in Neurobasal Medium supplemented with 2\% B27 Supplement and $2 \mathrm{mM} \mathrm{L}$-glutamine (Life Technologies, Milan, Italy) to allow the selective growth of neurons according to [24]. After 5 days of culture, neurons were plated according to experimental requirements.

Both astrocyte and neuron cultures were released from the culture plates by treatment with $0.5 \%$ trypsin in PBS containing $0.03 \%$ EDTA for $1 \mathrm{~min}$ and allowed to seed for at least $24 \mathrm{~h}$ before being used for the experiments.

2.2. Neuron Astrocyte Coculture. Neurons and astrocytes were separately cultured for 5 and 21 days, respectively. Then astrocytes were plated in transwells $(0.45 \mu \mathrm{M}$ pore size; $\mathrm{BD}$ Biosciences, Durham, NC, USA) while neurons were plated in multiwells as described below. The day after plating, inserts containing astrocytes were placed on the wells containing primary neurons and, after $24 \mathrm{~h}$, treated with oxaliplatin (Sequoia Research Products, Pangbourne, UK) in the presence or absence of $10 \mu \mathrm{M}$ PNU-282987 (PNU-282987; SigmaAldrich, Milan, Italy). In this modeling, although neurons and astrocytes face each other, they are separable, and the effect of soluble factors released from activated astrocytes on neurons can be studied, allowing separate analysis of neuronal and glial populations [25].

2.3. Cell Viability Assay. Cell viability was evaluated by the reduction of 3-(4,5-dimethylthiazol-2-yl)-2,5-diphenyltetrazolium bromide (MTT; Sigma-Aldrich, Milan, Italy) as an index of mitochondrial compartment functionality. For experiments in monocultures, primary neurons or astrocytes were plated in 96-well cell culture plates $\left(10^{4}\right.$ cells/well $)$ and grown until confluent. For experiments in coculture primary neurons were plated in 24 -well plates $\left(210^{5}\right.$ cells/well $)$ while primary astrocytes were plated in appropriate transwells (8 $10^{4}$ cells/well) and grown until confluence. Cells were treated for $48 \mathrm{~h}$ with oxaliplatin $(0.3-100 \mu \mathrm{M})$ in the presence or absence of PNU $(10 \mu \mathrm{M})$. After extensive washing, $1 \mathrm{mg} / \mathrm{mL}$ MTT was added to each well and incubated for $2 \mathrm{~h}$ at $37^{\circ} \mathrm{C}$. After washing, formazan crystals were dissolved in $100 \mu \mathrm{L}$ dimethyl sulfoxide. The absorbance was measured at $580 \mathrm{~nm}$. Experiments were performed in quadruplicate on at least three different cell batches.

2.4. Caspase-3 Activity. In monoculture experiments, neurons or astrocytes were plated in 6-well plates $\left(510^{5}\right.$ cells/well) and grown until confluence. In coculture experiments neurons were plated in 6-well plates $\left(710^{5}\right.$ cells/well) while astrocytes were plated in appropriate transwells $\left(4.510^{5}\right.$ cells/well). Incubation with increasing concentrations of oxaliplatin $(0.3-100 \mu \mathrm{M})$ was allowed for different times (4, 8 , and $48 \mathrm{~h}$ ) in the absence or presence of $10 \mu \mathrm{M}$ PNU. After treatment, cells were scraped in $100 \mu \mathrm{L}$ lysis buffer $(200 \mathrm{mM}$ Tris- $\mathrm{HCl}$ buffer, $\mathrm{pH} 7.5$, containing $2 \mathrm{M} \mathrm{NaCl}, 20 \mathrm{mM}$ EDTA, and $0.2 \%$ Triton X-100). Fifty $\mu \mathrm{L}$ of the supernatant was incubated with $25 \mu \mathrm{M}$ fluorogenic peptide caspase substrate rhodamine 110 bis(N-CBZ- $L$-aspartyl- $L$-glutamyl- $L$-valyl- $L$ aspartic acid amide) (Molecular Probes, Milan, Italy) at $25^{\circ} \mathrm{C}$ for $30 \mathrm{~min}$. The amount of cleaved substrate of each sample was measured in a 96-well plate fluorescence spectrometer (PerkinElmer; excitation at $496 \mathrm{~nm}$ and emission at $520 \mathrm{~nm}$ ). 
2.5. TGF- $\beta 1$ Dosage. In monoculture experiments neurons or astrocytes were plated in a 6 -well plate $\left(510^{5}\right.$ cells/well). In coculture experiments neurons were plated in 6-well cell culture plates $\left(710^{5}\right.$ cells/well), while astrocytes were plated in specific transwells $\left(4.510^{5}\right.$ cells/well). Cells were then treated with oxaliplatin $1 \mu \mathrm{M}$ for $48 \mathrm{~h}$ in the presence or absence of $10 \mu \mathrm{M}$ PNU. After treatment, the culture medium was collected and used for determining TGF- $\beta 1$ by ELISA kit (BioLegend, Inc., USA). Culture medium samples were activated by acidification and processed according to the manufacturer protocol. The absorbance was measured at $450 \mathrm{~nm}$. Declared assay sensibility is $1 \mathrm{pg} / \mathrm{mL}$.

2.6. Pyruvate Assay. In order to evaluate astrocyte metabolism, pyruvate intracellular concentration was measured. The dosage is based on the conversion of pyruvate to acetyl phosphate, hydrogen peroxide, and carbon dioxide catalyzed by pyruvate oxidase. In the presence of horseradish peroxidase, $\mathrm{H}_{2} \mathrm{O}_{2}$ reacts stoichiometrically with 10-acetyl-3,7dihydroxyphenoxazine to produce resorufin. Resorufin fluorescence is analyzed with an excitation wavelength between 530 and $540 \mathrm{~nm}$ and an emission wavelength between 585 and $595 \mathrm{~nm}$.

Astrocytes were plated in a 6-well plate $\left(510^{5}\right.$ cells/well). After treatments $(1 \mu \mathrm{M}$ oxaliplatin for $48 \mathrm{~h}$ in the presence or absence of $10 \mu \mathrm{M}$ PNU) cells were scraped. The cell pellet was treated with $0.5 \mathrm{~mL} 0.25 \mathrm{M}$ metaphosphoric acid on ice for $5 \mathrm{~min}$ to deproteinate the sample. After centrifugation $\left(10000 \times \mathrm{g}\right.$ for $5 \mathrm{~min}$ at $\left.4^{\circ} \mathrm{C}\right)$, the pellet was neutralized by adding $25 \mu \mathrm{L} \mathrm{K}_{2} \mathrm{CO}_{3}(5 \mathrm{M})$. After centrifugation, the supernatant was analyzed following the manufacturer's instruction (Cayman, Ann Arbor, MI, USA).

2.7. Western Blot Analysis. After incubation, astrocyte cell cultures were washed once with PBS and scraped on ice with lysis buffer containing $50 \mathrm{mM}$ Tris- $\mathrm{HCl} \mathrm{pH} \mathrm{8.0,150} \mathrm{mM}$ $\mathrm{NaCl}, 1 \mathrm{mM}$ EDTA, $0.5 \%$ Triton X-100, and Complete Protease Inhibitor (Roche, Milan, Italy). Suspensions were then collected, subjected to a freeze-thaw cycle, and centrifuged at $13,0006 \mathrm{~g}$ for $10 \mathrm{~min}$ at $4^{\circ} \mathrm{C}$. Protein concentrations were quantified by bicinchoninic acid assay. Forty $\mu \mathrm{g}$ of each sample was resolved with $10 \%$ SDS-PAGE before electrophoretic transfer onto nitrocellulose membranes (Bio-Rad, Milan, Italy). Membranes were blocked with 5\% nonfat dry milk in PBS containing $0.1 \%$ Tween 20 (PBST) and then probed overnight at $4^{\circ} \mathrm{C}$ with primary antibody specific versus glutamine synthetase $(1: 2500 ; 45 \mathrm{kDa}$; Millipore, Billerica, MA, USA) or GAPDH (1:1000; $38 \mathrm{kDa}$; Cell Signaling, Boston, MA, USA). Membranes were then incubated for 1 hour in PBST containing the appropriate horseradish peroxidaseconjugated secondary anti-rabbit (1:5000; Cell Signaling, USA) or anti-mouse antibody $(1: 2000$; Santa Cruz, USA). ECL (Enhanced Chemiluminescence Pierce, Rockford, IL, USA) was used to visualize the peroxidase-coated bands. Densitometric analysis was performed using the "ImageJ" analysis software (ImageJ, NIH, Bethesda, MD, USA) and results were normalized to GAPDH immunoreactivity as internal control. Values were reported as percentages in comparison to control which was arbitrarily fixed at $100 \%$.

2.8. Statistical Analysis. Results were expressed as mean \pm S.E.M. and analysis of variance (ANOVA) was performed. A Bonferroni significant difference procedure was used as post hoc comparison. All assessments were made by researchers blinded to cell treatments. Data were analyzed using the "Origin 8.1" software (OriginLab, Northampton, USA).

\section{Results}

Oxaliplatin induced a concentration-dependent decrease of neuron viability after $48 \mathrm{~h}$ incubation. As shown in Figure 1(a) (neuron, monoculture), significant effects were evoked by $1 \mu \mathrm{M}$ oxaliplatin ( $40 \%$ decrease) reaching a plateau for decreased viability at concentrations higher than $10 \mu \mathrm{M}$ (about 70\% decrease). The same cell treatment increased the activity of caspase- 3 in a concentration-dependent way: $1 \mu \mathrm{M}$ oxaliplatin enhanced the enzymatic activity by about 1.7fold and $30 \mu \mathrm{M}$ by 6 -fold (Figure 1(b), neuron monoculture). Astrocytes appeared more resistant to oxaliplatin toxicity since cell viability was decreased by about $40 \%$ and $55 \%$ after treatment with $10 \mu \mathrm{M}$ and $100 \mu \mathrm{M}$ oxaliplatin, respectively (Figure 1(a), astrocyte monoculture). One $\mu \mathrm{M}$ oxaliplatin (48 $\mathrm{h}$ incubation) was unable to modify both cell viability (Figure 1(b), astrocyte monoculture) and apoptotic processes $(103.4 \pm 12.5 \%$ versus control $100.0 \pm 0.13 \%)$.

Figure 1 (neuron coculture) shows the response of neurons to oxaliplatin treatment when cocultured with astrocytes. As compared to neuron monoculture, the presence of astrocytes did not significantly modify oxaliplatin toxicity evaluated as cell viability as well as caspase-3 activity. When neuron astrocyte cocultures were incubated with the $\alpha 7$ nAChR agonist PNU $(10 \mu \mathrm{M})$, the neuronal damage was strongly reduced (Figure 2). As shown, PNU increased neuron viability by $10 \%$ and $20 \%$ in cocultures treated with 1 and $10 \mu \mathrm{M}$ oxaliplatin, respectively (Figure 2(a)). Moreover, PNU completely prevented the activation of caspase- 3 up to $30 \mu \mathrm{M}$ oxaliplatin (Figure 2(b)). In the absence of astrocytes, PNU did not protect neurons from oxaliplatin neurotoxicity since cell viability of neuron monoculture was reduced by $40 \%$ after $48 \mathrm{~h}$ incubation with $1 \mu \mathrm{M}$ oxaliplatin and by $70 \%$ for the concentration range 10-100 $\mu \mathrm{M}$ (Figure 3(a)). Similarly, $10 \mu \mathrm{M}$ PNU did not decrease caspase-3 activity induced by $48 \mathrm{~h}$ incubation with $1 \mu \mathrm{M}$ oxaliplatin (Figure 3(b)).

Figure 4 shows TGF- $\beta 1$ concentrations in culture media after $48 \mathrm{~h}$ incubation (oxaliplatin $1 \mu \mathrm{M}$ ). The basal production of TGF- $\beta 1$ was $0.14 \pm 0.05 \mathrm{pg} / \mathrm{mL}$ in neuron monoculture and $13.2 \pm 0.99 \mathrm{pg} / \mathrm{mL}$ in astrocytes. Neither oxaliplatin nor PNU significantly altered these levels. In the medium of neuron astrocyte coculture, $3.93 \pm 0.45 \mathrm{pg} / \mathrm{mL}$ was basally detected $(48 \mathrm{~h})$. Oxaliplatin (1 and $10 \mu \mathrm{M})$ increased TGF- $\beta 1$ release by about 2 - and 3-fold with respect to control values. PNU $(10 \mu \mathrm{M})$ potentiated the stimulatory effect of oxaliplatin increasing the cytokine levels by 4-, 6-, and 8-fold in the presence of oxaliplatin of $0.3,1$, and $10 \mu \mathrm{M}$ (Figure 4). 


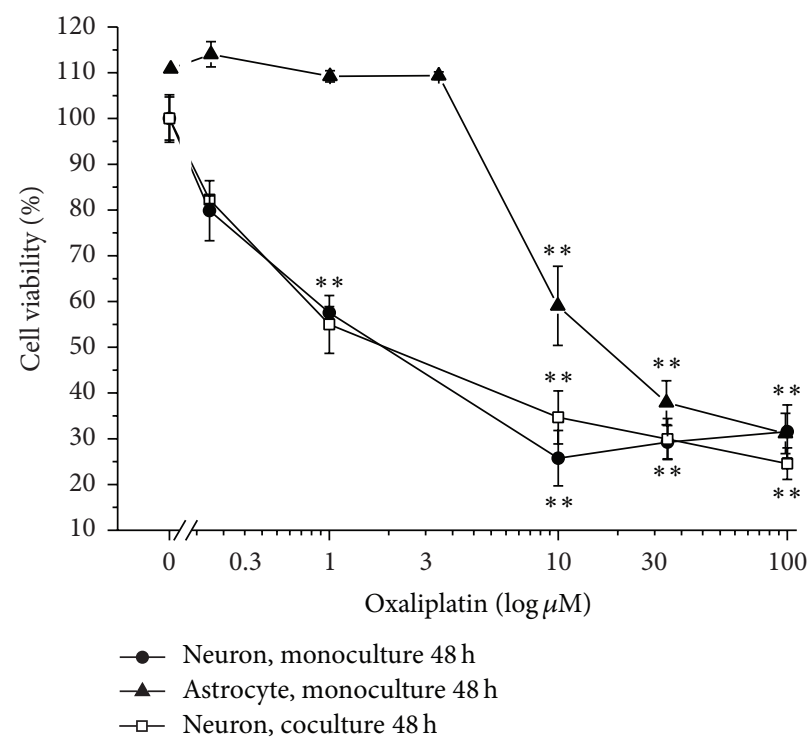

(a)

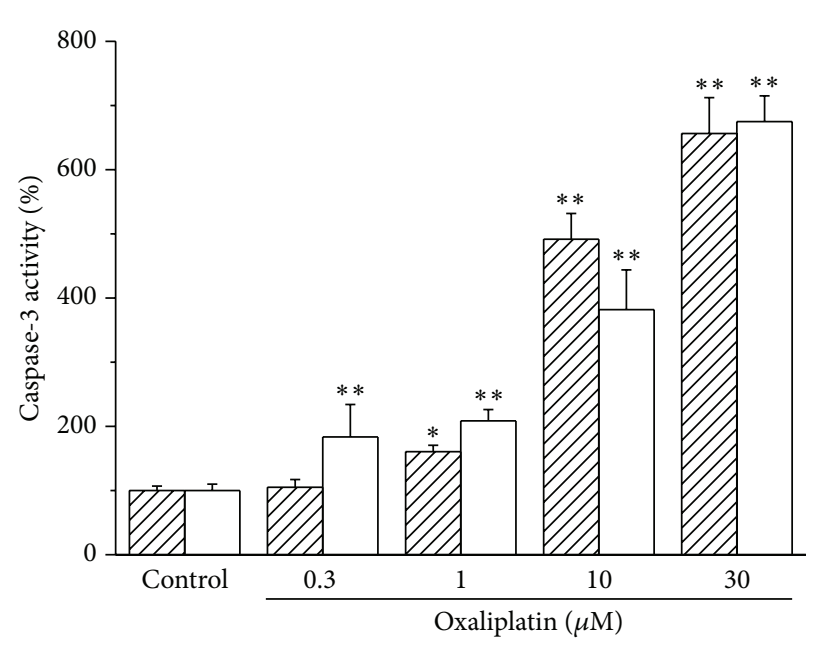

VIIA Neuron, monoculture $48 \mathrm{~h}$ Neuron, coculture $48 \mathrm{~h}$

(b)

FIGURE 1: Oxaliplatin toxicity in mono- and cocultures. (a) Cell viability. Neuron monoculture $\left(10^{4}\right.$ cells/well), astrocyte monoculture (10 ${ }^{4}$ cells/well), and neuron astrocyte coculture ( $210^{5}$ neurons/well and $810^{4}$ astrocytes/well) were incubated with oxaliplatin ( $\left.0.3-100 \mu \mathrm{M}\right)$ for $48 \mathrm{~h}$. Viability of neurons in coculture was quantified by MTT assay and compared with the viability of neurons or astrocytes in monoculture. Values are expressed in percentage of control absorbance ( 0 oxaliplatin) as mean \pm S.E.M. of 6 experiments. Control condition absorbance was fixed to $100 \%$. ${ }^{* *} P<0.01$ versus control. (b) Caspase-3 activity. Neuron monoculture $\left(710^{5}\right.$ cells/well) or neuron astrocyte coculture (7 $10^{5}$ neurons/well and $4.510^{5}$ astrocytes/well) was incubated with oxaliplatin $(0.3-100 \mu \mathrm{M})$ for $48 \mathrm{~h}$. The enzymatic activity of neuronal component of the coculture was compared to that of neuron monocultures. The enzymatic activity was measured by a fluorescent assay. Values are expressed as percent of control caspase- 3 activity arbitrarily set as $100 \%$. Bars represent mean \pm S.E.M. of 3 experiments. One-way ANOVA was performed followed by a Bonferroni significant difference procedure. ${ }^{*} P<0.05$ and ${ }^{* *} P<0.01$ versus control.

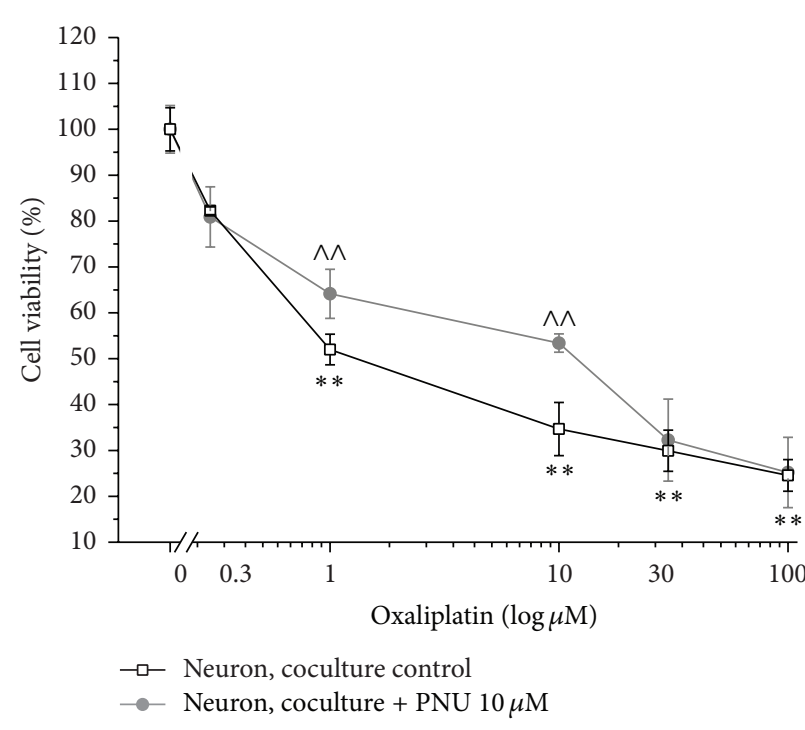

(a)

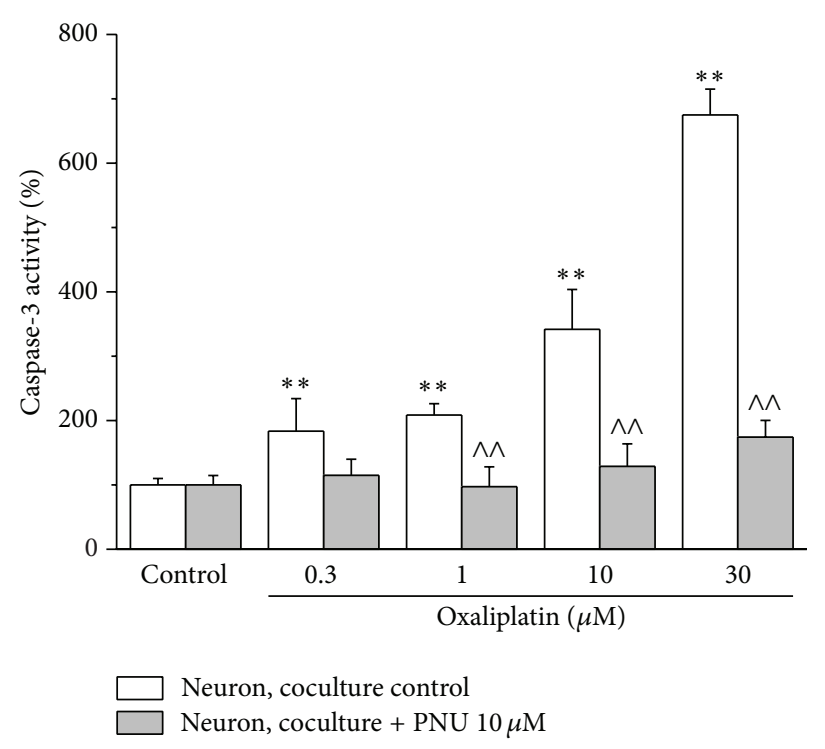

(b)

FIGURE 2: Effect of PNU in cocultures. (a) Cell viability. Neuron astrocyte coculture $\left(210^{5}\right.$ neurons/well and $810^{4}$ astrocytes/well) was incubated with oxaliplatin $(0.3-100 \mu \mathrm{M})$ in the absence or presence of $10 \mu \mathrm{M}$ PNU for $48 \mathrm{~h}$. Neuronal cell viability was quantified by MTT assay. Values are expressed in percentage of control absorbance as mean \pm S.E.M. of 6 experiments. Control condition absorbance was fixed to $100 \%$. ${ }^{* *} P<0.01$ versus control; ${ }^{\wedge} P<0.01$ versus oxaliplatin treatment. (b) Caspase- 3 activity. Neuron astrocyte coculture $\left(710^{5}\right.$ neurons/well and $4.510^{5}$ astrocytes/well) was incubated with oxaliplatin (0.3-100 $\left.\mu \mathrm{M}\right)$ in the absence or presence of $10 \mu \mathrm{M}$ PNU for $48 \mathrm{~h}$. Neuronal enzymatic activity was measured by a fluorescent assay. Values are expressed as percent of control caspase-3 activity arbitrarily set as $100 \%$. Bars represent mean \pm S.E.M. of 3 experiments. One-way ANOVA was performed followed by a Bonferroni significant difference procedure. ${ }^{* *} P<0.01$ versus control; ${ }^{\wedge} P<0.01$ versus oxaliplatin treatment. 


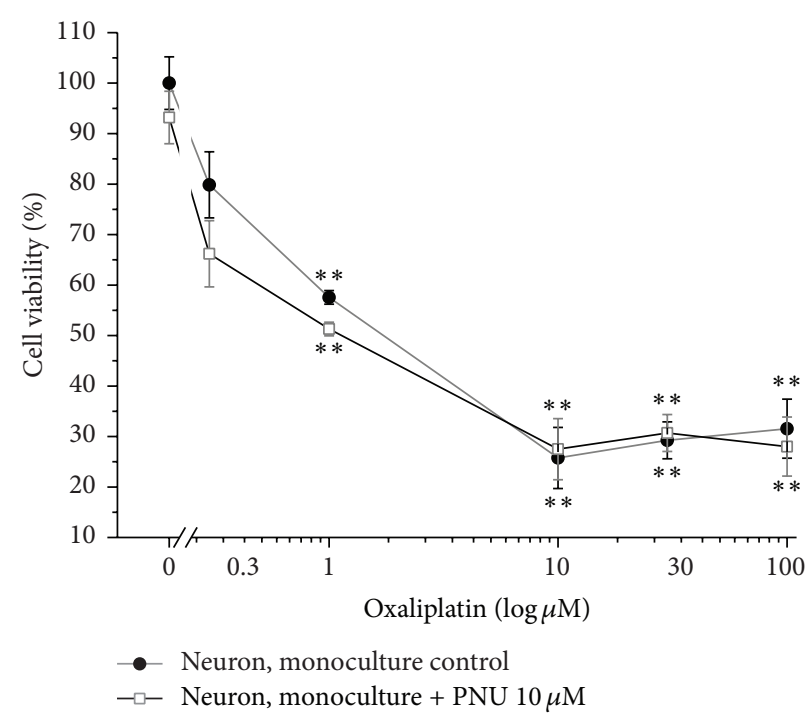

(a)

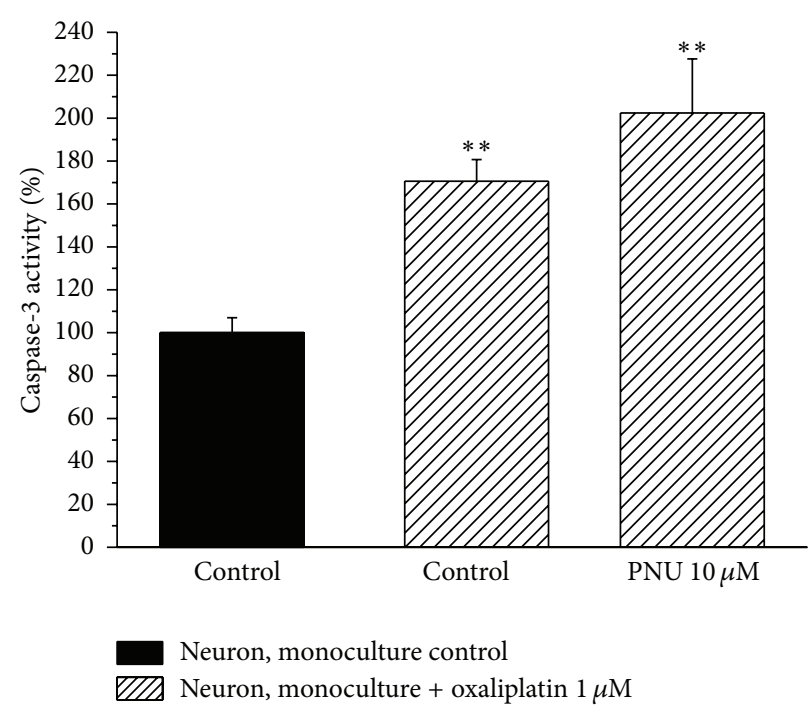

(b)

FIGURE 3: Effect of PNU in neuron monoculture. (a) Cell viability. Neurons ( $10^{4}$ cells/well) were incubated with oxaliplatin ( $\left.0.3-100 \mu \mathrm{M}\right)$ in the absence or presence of $10 \mu \mathrm{M}$ PNU for $48 \mathrm{~h}$. Viability was quantified by MTT assay. Values are expressed in percentage of control absorbance as mean \pm S.E.M. of 6 experiments. Control condition absorbance was fixed to $100 \% .{ }^{* *} P<0.01$ versus control. (b) Caspase-3 activity. Neurons $\left(710^{5}\right.$ cells/well) were incubated with $1 \mu \mathrm{M}$ oxaliplatin in the absence or presence of $10 \mu \mathrm{M}$ PNU for $48 \mathrm{~h}$. The enzymatic activity was measured by a fluorescent assay. Values are expressed as percent of control caspase- 3 activity arbitrarily set as $100 \%$. One-way ANOVA was performed followed by a Bonferroni significant difference procedure. Bars represent mean \pm S.E.M. of 3 experiments. ${ }^{* *} P<0.01$ versus control.

TABLe 1: Astrocyte monoculture. Pyruvate intracellular levels.

\begin{tabular}{lccc}
\hline \multicolumn{4}{c}{ Pyruvate $(\%)$} \\
Control & $\begin{array}{c}\text { Oxaliplatin } \\
(1 \mu \mathrm{M})\end{array}$ & $\begin{array}{c}\text { PNU } \\
(10 \mu \mathrm{M})\end{array}$ & $\begin{array}{c}\text { Oxaliplatin }(1 \mu \mathrm{M})+ \\
\text { PNU }(10 \mu \mathrm{M})\end{array}$ \\
\hline $100.0 \pm 16.3$ & $545.9 \pm 56.7^{* *}$ & $129.8 \pm 25.3$ & $496.5 \pm 38.2^{* *}$
\end{tabular}

Pyruvate intracellular concentration was measured in astrocyte monoculture. Cells were treated with $1 \mu \mathrm{M}$ oxaliplatin $(48 \mathrm{~h})$ in the absence or presence of $10 \mu \mathrm{M}$ PNU. Values are expressed in percentage of control as mean \pm S.E.M. of 6 experiments. Control condition was fixed to $100 \%$. Oneway ANOVA was performed followed by a Bonferroni significant difference procedure. ${ }^{* *} P<0.01$ versus control.

In Table 1, the intracellular concentrations of pyruvate in astrocytes are shown. Oxaliplatin $(1 \mu \mathrm{M}, 48 \mathrm{~h})$ increased pyruvate by about 5 -fold; this effect was not altered in the presence of $10 \mu \mathrm{M}$ PNU. PNU per se was not able to significantly modify basal pyruvate levels.

Glutamine synthetase expression levels were evaluated in astrocytes by western blot (Figure 5). After $48 \mathrm{~h}$, oxaliplatin $(1 \mu \mathrm{M})$ and PNU $(10 \mu \mathrm{M})$ increased the enzyme expression by 2.5- and 3-fold, respectively. The concomitant treatment with oxaliplatin and PNU induced a 2.4-fold increase in glutamine synthetase expression (Figure 5).

\section{Discussion}

The present results highlight the neuronal protective effect induced by the $\alpha 7 \mathrm{nAChR}$ stimulation. The presence of astrocytes is needful to evoke the protective effect of PNU against the oxaliplatin neurotoxicity. In a rat model of oxaliplatin neuropathy ( $2.4 \mathrm{mg} \mathrm{kg}^{-1}$ intraperitoneally, daily for 21 days, according to [26]), we have previously described a painful condition characterized by neuronal damage associated with the activation of glial cells (in particular astrocytes) in spinal cord and in the "pain matrix" areas [11]. In this condition, the inorganic platinum plasmatic concentration is about $18 \mu \mathrm{M}$ [27]. Assuming the integrity of the blood-brain barrier, oxaliplatin has about $5 \%$ distribution in the central nervous system (CNS) [28, 29] allowing hypothesizing a concentration near to $1 \mu \mathrm{M}$. To note, the animal experimental protocol is consistent with the clinical use of the antitumor drug [27]. In the present cell culture experiments, neurons are more prone than glia to oxaliplatin damage since both cell mortality and apoptosis are induced by lower concentrations in neurons than in astrocytes. In particular, the incubation for $48 \mathrm{~h}$ with $1 \mu \mathrm{M}$ oxaliplatin (a concentration in agreement with the CNS theoretical one of in vivo experiments) impairs neurons without negatively affecting glia.

Astrocytes are generally less susceptible to injuries than neurons and can exert neuroprotective effects $[13,30]$; on the other hand, astroglia is derived from a neuroectoderm lineage and supports the maintenance of central nervous system homeostasis [31]. Astrocyte activation can protect neurons by preserving bioenergetics [32], providing a trophic support [33], preventing excitatory neurotoxicity [34, 35], and modulating free radical oxidation $[36,37]$ and apoptosis [38] in neurons. Unfortunately, in neuropathic conditions dysfunctional glial cells no longer maintain homeostasis and even contribute to nervous circuit alterations $[12,39]$. In 


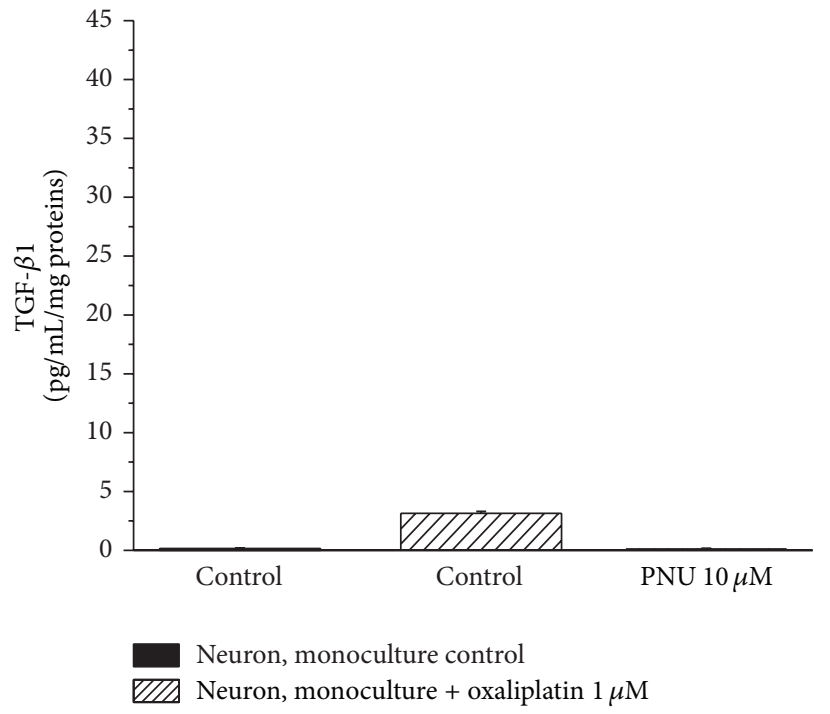

(a)

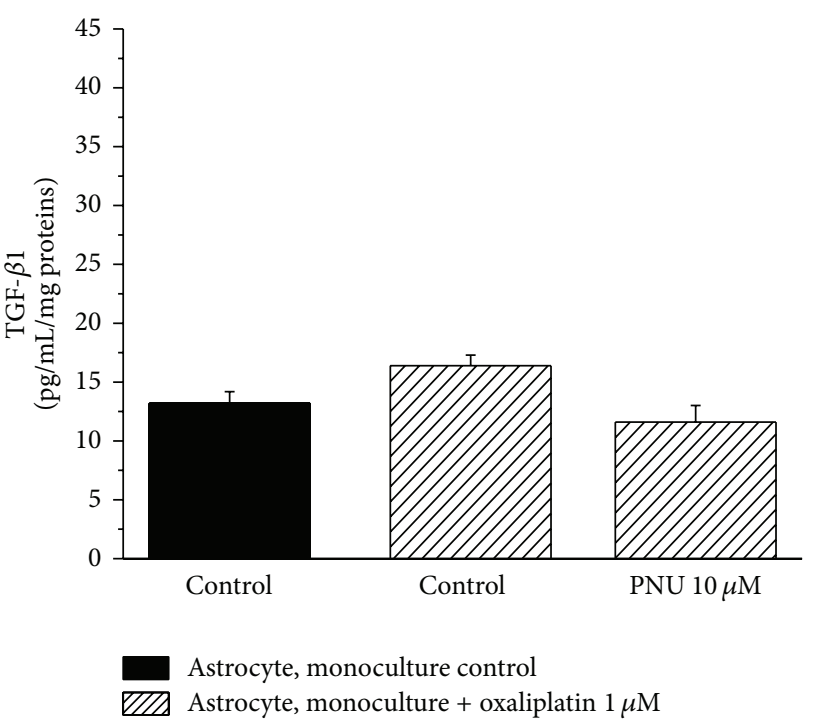

(b)

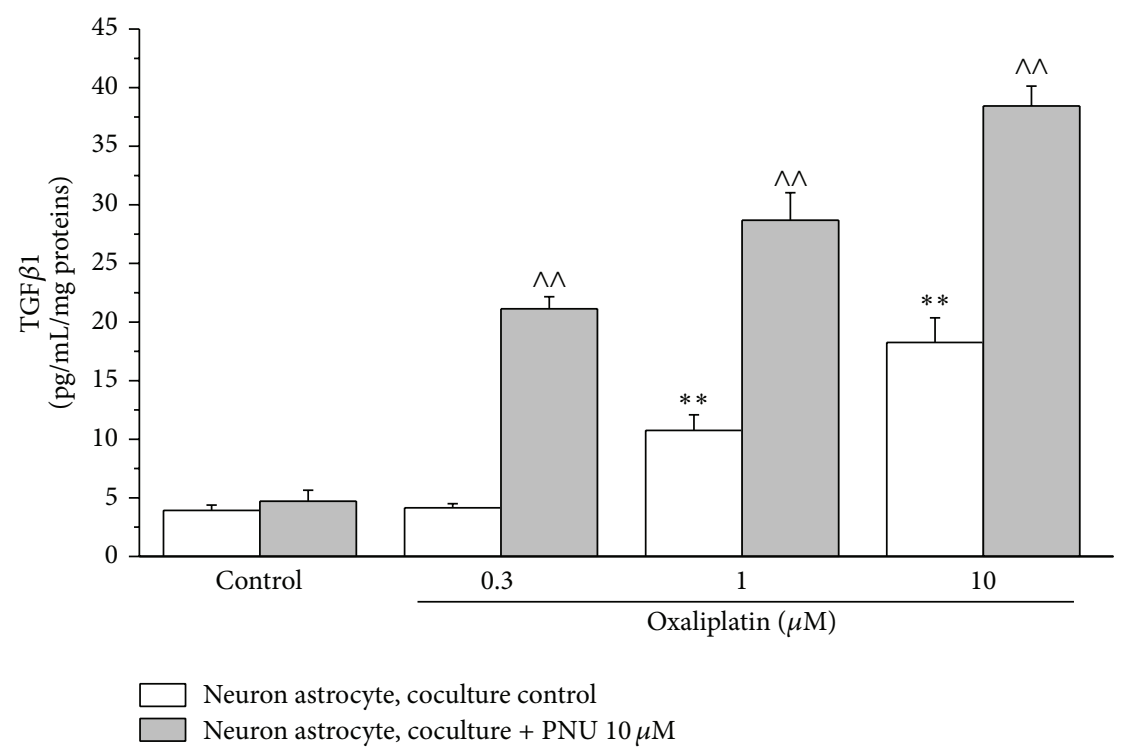

(c)

FIGURE 4: TGF- $\beta 1$ dosage. The concentration of the anti-inflammatory cytokine TGF- $\beta 1$ was measured in the culture medium of (a) neuron, (b) astrocyte monoculture, and (c) neuron astrocyte coculture. ((a) and (b)) Cells were treated with $1 \mu \mathrm{M}$ oxaliplatin ( $48 \mathrm{~h})$ in the absence or presence of $10 \mu \mathrm{M}$ PNU. (c) Cocultures were treated with increasing concentrations of oxaliplatin $(0.3,1$, and $10 \mu \mathrm{M})$ in the absence or presence of $10 \mu \mathrm{M}$ PNU. Results are expressed as pg/mL of TGF- $\beta 1$ per mg of proteins. Values are expressed as the mean \pm S.E.M. of 6 experiments. One-way ANOVA was performed followed by a Bonferroni significant difference procedure. ${ }^{* *} P<0.01$ versus control; ${ }^{M} P<0.01$ versus oxaliplatin treatment.

the present study, oxaliplatin increases pyruvate intracellular concentration of astrocytes and this increase might be an attempt to counterbalance oxaliplatin toxicity. In astrocytes, pyruvate derived from glucose may be oxidized in mitochondria to produce ATP by the tricarboxylic acid cycle [40]. Therefore, an increase in intracellular pyruvate suggests the activation of the energy metabolism. Nevertheless, astrocytes per se are not able to prevent the neuronal damage induced by oxaliplatin and the $\alpha 7 \mathrm{nAChR}$ stimulation is needed to improve the astrocyte protective role.
The neuroprotective role of $\alpha 7 \mathrm{nAChR}$ has been described in vitro [41] and in vivo in both the peripheral $[18,42]$ and central nervous system [43]. $\alpha 7 \mathrm{nAChR}$-dependent activation of glial cells is observed [17] and $\alpha 7 \mathrm{nAChR}$ agonists are able to preserve nervous tissue in neuropathic states $[17,42]$ as well as in neurodegenerative conditions such as Parkinson's and Alzheimer's diseases [43]. In neurons, survival signal transduction by the phosphatidylinositol 3-kinase/AKT pathway (PI3K/AKT), the Janus kinase-2/signal transducer and activator of transcription-3 (JAK2/STAT3) pathway, and 


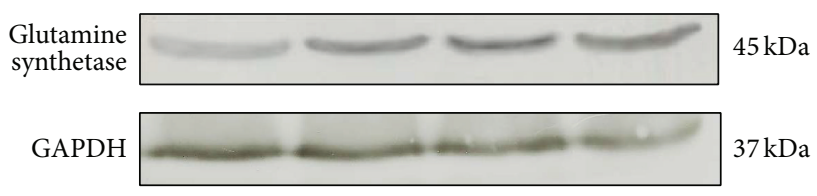

(a)
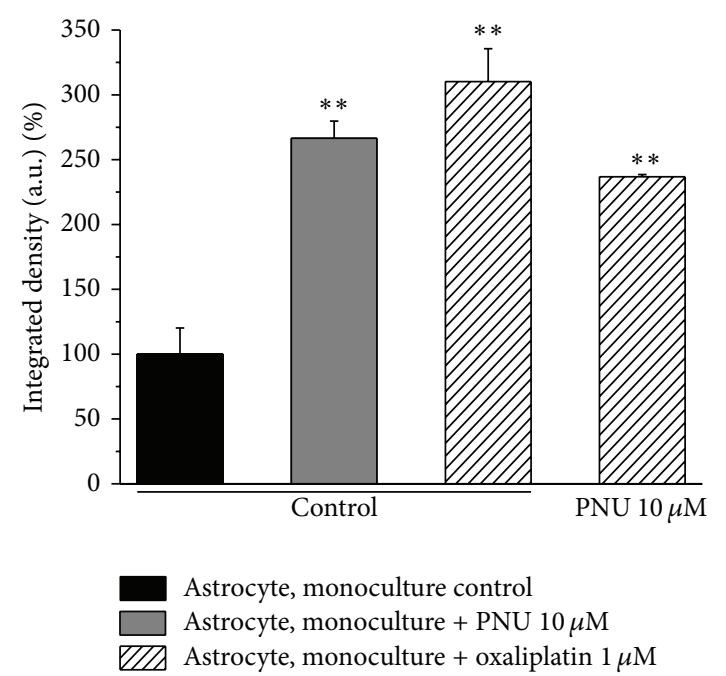

(b)

FIGURE 5: Glutamine synthetase expression level in astrocyte monoculture. Astrocytes were separately treated with $1 \mu \mathrm{M}$ oxaliplatin, $10 \mu \mathrm{M}$ PNU or coincubated with oxaliplatin and PNU for $48 \mathrm{~h}$. Densitometric analysis (b) and representative western blot (a) are shown. GAPDH normalization was performed for each sample. Values are expressed as the mean \pm S.E.M. of 3 experiments. Oneway ANOVA was performed followed by a Bonferroni significant difference procedure. ${ }^{* *} P<0.01$ versus control.

the mitogen activated protein kinase/extracellular signal regulated kinase (MAPK/ERK) pathway participate in $\alpha 7$ nAChR-mediated neuroprotection $[44,45]$. Activation of microglial $\alpha 7 \mathrm{nAChR}$ during neuroinflammation modulates inflammatory cytokine (like TNF- $\alpha$ ) release with protective effects on neurons [46] and the $\alpha 7 \mathrm{nAChR}$-dependent $\mathrm{Ca}^{2+}$ influx into microglia may stimulate $\beta$-amyloid phagocytosis through actin reorganization [45]. As regards astrocytes, the $\alpha 7 \mathrm{nAChR}$ activation is able to inhibit TNF- $\alpha$ release and MAPK in astrocytes activated by 1-methyl-4phenylpyridinium ion (MPP+) or lipopolysaccharide [47]. Moreover, $\alpha 7 \mathrm{nAChR}$ is protective for astrocytes since, through the stimulation of $\alpha 7 \mathrm{nAChR}$, nicotine suppresses astrocyte apoptosis induced by oxidative stress [47]. Nevertheless, insufficient information exists about the positive role that the $\alpha 7 \mathrm{nAChR}$ stimulation mediates in astrocyte neuroprotective signaling. The present results show that the $\alpha 7 \mathrm{nAChR}$ agonist PNU is able to rescue neurons from oxaliplatin toxicity only in the presence of astrocyte cells highlighting the central role of astroglia in the protective signals evoked by $\alpha 7 \mathrm{nAChR}$. Neuron survival and inhibition of apoptotic processes are correlated with enhanced release of TGF- $\beta 1$ in coculture. The basal level of the growth factor is higher in astrocytes than in neurons but in monoculture neither oxaliplatin nor PNU is able to evoke a cytokine modulation. Differently, in coculture TGF- $\beta 1$ increases up to 8 -fold in the presence of PNU and, at a lesser extent, by oxaliplatin per se. TGF- $\beta 1$ is a member of the TGF$\beta$ superfamily and it has been implicated in such diverse processes as regulation of growth, differentiation, extracellular matrix formation, and immune regulation as well as induction of neuronal survival and repair following injury $[48,49]$. TGF- $\beta 1$ is recognized as determinant in the protective astrocytic functions for neuron homeostasis by the c-Jun/AP-1 transcription factor pathway [50]. The role of TGF- $\beta 1$ in the orchestration of repair processes has been evidenced in many neurodegenerative diseases and following vascular accident in the brain [51-53]; furthermore, TGF- $\beta 1$ attenuates spinal neuroinflammation and excitatory amino acid system in rats with neuropathic pain [54], leading to pain relief after intrathecal administration [55]. TGF- $\beta 1$ inhibits the production and release of proinflammatory cytokines, nitric oxide, and oxygen free radicals $[56,57]$. In addition, TGF- $\beta 1$ modulates the high synaptic glutamate levels associated with neurotoxic and neurodegenerative processes [58], increasing the expression of the glutamate-aspartate transporter (GLAST [59]) expressed preferentially in astrocytes [60]. Besides glutamate transporters, the glutamateglutamine metabolic cycle between astrocytes and neurons is believed to be vital for preventing neuronal excitotoxicity [61]. In the astrocytic intracellular milieu glutamate is rapidly converted to glutamine by glutamine synthetase [62], an astrocyte-specific enzyme [63]. Glutamine can be shuttled out of glial cells and taken up by neurons for use by glutaminase in the glutamine cycle [64]. The coupling of glutamine synthetase and glutamine traffic from glia to neurons permits glutamate passage in the extracellular compartment in a nonneuroactive form (glutamine) thus avoiding toxicity [65]. Recently, Zou and coworkers [66] have demonstrated that the downregulation of glutamine synthetase reduces astrocyte protection against glutamate excitotoxicity to neurons. In the present study, glutamine synthetase expression is significantly upregulated in astrocyte cells after oxaliplatin treatment, suggesting that glia could preserve neurons from glutamateinduced excitotoxicity through this mechanism. This protective response is promoted by cell incubation with PNU alone and maintained after the cotreatment with oxaliplatin + PNU. On the other hand, glutamine synthetase may be stimulated by the increased level of pyruvate. Pyruvate is substrate of pyruvate carboxylase and pyruvate dehydrogenase forming the tricarboxylic acid cycle constituent citrate, from which glutamate is generated via $\alpha$-ketoglutarate [67]. PNU per se does not alter pyruvate level; therefore, astrocytes stimulated by this $\alpha 7 \mathrm{nAChR}$ agonist might optimize their protective role without favoring glutamate toxicity.

\section{Conclusions}

These results are a contribution to the comprehension of the neuroprotective signaling evoked by the $\alpha 7 \mathrm{nAChR}$ stimulation. The positive role of astrocyte activation is highlighted concomitantly with the increase of TGF- $\beta 1$ and glutamine synthetase, two biological mediators of neuroprotection also 
able to mediate pain relief. The $\alpha 7 \mathrm{nAChR}$ modulation of the pathological neuron-glia cross talk could control oxaliplatin neurotoxicity.

\section{Conflict of Interests}

The authors declare that there is no conflict of interests regarding the publication of this paper.

\section{Acknowledgments}

This research was funded by the Italian Ministry of Instruction, University and Research (MIUR) and University of Florence.

\section{References}

[1] G. Kannarkat, E. E. Lasher, and D. Schiff, "Neurologic complications of chemotherapy agents," Current Opinion in Neurology, vol. 20, no. 6, pp. 719-725, 2007.

[2] S. Wolf, D. Barton, L. Kottschade, A. Grothey, and C. Loprinzi, "Chemotherapy-induced peripheral neuropathy: prevention and treatment strategies," European Journal of Cancer, vol. 44, no. 11, pp. 1507-1515, 2008.

[3] N. C. Miltenburg and W. Boogerd, "Chemotherapy-induced neuropathy: a comprehensive survey," Cancer Treatment Reviews, vol. 40, no. 7, pp. 872-882, 2014.

[4] A. Weickhardt, K. Wells, and W. Messersmith, "Oxaliplatininduced neuropathy in colorectal cancer," Journal of Oncology, vol. 2011, Article ID 201593, 7 pages, 2011.

[5] A. Grothey, D. A. Nikcevich, J. A. Sloan et al., "Intravenous calcium and magnesium for oxaliplatin-induced sensory neurotoxicity in adjuvant colon cancer: NCCTG N04C7," Journal of Clinical Oncology, vol. 29, no. 4, pp. 421-427, 2011.

[6] M. W. Saif and J. Reardon, "Management of oxaliplatin-induced peripheral neuropathy," Journal of Therapeutics and Clinical Risk Management, vol. 1, no. 4, pp. 249-258, 2014.

[7] K. K. Baek, J. Lee, S. H. Park et al., "Oxaliplatin-induced chronic peripheral neurotoxicity: a prospective analysis in patients with colorectal cancer," Cancer Research and Treatment, vol. 42, no. 4, pp. 185-190, 2010.

[8] A. Avan, T. J. Postma, C. Ceresa et al., "Platinum-induced neurotoxicity and preventive strategies: past, present, and future," The Oncologist, vol. 20, no. 4, pp. 411-432, 2015.

[9] L. Di Cesare Mannelli, M. Zanardelli, P. Failli, and C. Ghelardini, "Oxaliplatin-induced neuropathy: oxidative stress as pathological mechanism. Protective effect of silibinin," Journal of Pain, vol. 13, no. 3, pp. 276-284, 2012.

[10] D. L. Hershman, C. Lacchetti, R. H. Dworkin et al., "Prevention and management of chemotherapy-induced peripheral neuropathy in survivors of adult cancers: American Society of Clinical Oncology clinical practice guideline," Journal of Clinical Oncology, vol. 32, no. 18, pp. 1941-1967, 2014.

[11] L. Di Cesare Mannelli, A. Pacini, L. Bonaccini, M. Zanardelli, T. Mello, and C. Ghelardini, "Morphologic features and glial activation in rat oxaliplatin-dependent neuropathic pain," The Journal of Pain, vol. 14, no. 12, pp. 1585-1600, 2013.

[12] L. Di Cesare Mannelli, A. Pacini, L. Micheli, A. Tani, M. Zanardelli, and C. Ghelardini, "Glial role in oxaliplatin-induced neuropathic pain," Experimental Neurology, vol. 261, pp. 22-33, 2014.
[13] E. D. Milligan and L. R. Watkins, "Pathological and protective roles of glia in chronic pain," Nature Reviews Neuroscience, vol. 10, no. 1, pp. 23-36, 2009.

[14] A. Boivin, I. Pineau, B. Barrette et al., "Toll-like receptor signaling is critical for Wallerian degeneration and functional recovery after peripheral nerve injury," The Journal of Neuroscience, vol. 27, no. 46, pp. 12565-12576, 2007.

[15] M. S. Thomsen and J. D. Mikkelsen, "The $\alpha 7$ nicotinic acetylcholine receptor complex: one, two or multiple drug targets?" Current Drug Targets, vol. 13, no. 5, pp. 707-720, 2012.

[16] K. T. Dineley, A. A. Pandya, and J. L. Yakel, "Nicotinic ACh receptors as therapeutic targets in CNS disorders," Trends in Pharmacological Sciences, vol. 36, no. 2, pp. 96-108, 2015.

[17] L. Di Cesare Mannelli, A. Pacini, C. Matera et al., "Involvement of $\alpha 7 \mathrm{nAChR}$ subtype in rat oxaliplatin-induced neuropathy: effects of selective activation," Neuropharmacology, vol. 79, pp. 37-48, 2014.

[18] A. L. Bodnar, L. A. Cortes-Burgos, K. K. Cook et al., "Discovery and structure-activity relationship of quinuclidine benzamides as agonists of alpha7 nicotinic acetylcholine receptors," Journal of Medicinal Chemistry, vol. 48, no. 4, pp. 905-908, 2005.

[19] M. Hajós, R. S. Hurst, W. E. Hoffmann et al., “The selective alpha7 nicotinic acetylcholine receptor agonist PNU-282987 [N-[(3R)-1-azabicyclo[2.2.2] oct-3-yl]-4-chlorobenzamide hydrochloride] enhances GABAergic synaptic activity in brain slices and restores auditory gating deficits in anesthetized rats," Journal of Pharmacology and Experimental Therapeutics, vol. 312, no. 3, pp. 1213-1222, 2005.

[20] J. Malysz, J. H. Grønlien, D. B. Timmermann et al., "Evaluation of alpha7 nicotinic acetylcholine receptor agonists and positive allosteric modulators using the parallel oocyte electrophysiology test station," Assay and Drug Development Technologies, vol. 7, no. 4, pp. 374-390, 2009.

[21] L. Di Cesare Mannelli, M. Zanardelli, P. Failli, and C. Ghelardini, "Oxaliplatin-induced oxidative stress in nervous systemderived cellular models: could it correlate with in vivo neuropathy?" Free Radical Biology and Medicine, vol. 61, pp. 143-150, 2013.

[22] K. D. McCarthy and J. de Vellis, "Preparation of separate astroglial and oligodendroglial cell cultures from rat cerebral tissue," Journal of Cell Biology, vol. 85, no. 3, pp. 890-902, 1980.

[23] L. Di Cesare Mannelli, D. Bani, A. Bencini et al., "Therapeutic effects of the superoxide dismutase mimetic compound $\mathrm{Mn}^{I I} \mathrm{Me}_{2} \mathrm{DO} 2 \mathrm{~A}$ on experimental articular pain in rats," Mediators of Inflammation, vol. 2013, Article ID 905360, 11 pages, 2013.

[24] H. R. Quintá and M. D. Galigniana, "The neuroregenerative mechanism mediated by the Hsp90-binding immunophilin FKBP52 resembles the early steps of neuronal differentiation," British Journal of Pharmacology, vol. 166, no. 2, pp. 637-649, 2012.

[25] A. Jana and K. Pahan, "Fibrillar amyloid- $\beta$-activated human astroglia kill primary human neurons via neutral sphingomyelinase: implications for Alzheimer's disease," Journal of Neuroscience, vol. 30, no. 38, pp. 12676-12689, 2010.

[26] G. Cavaletti, G. Tredici, M. G. Petruccioli et al., "Effects of different schedules of oxaliplatin treatment on the peripheral nervous system of the rat," European Journal of Cancer, vol. 37, no. 18, pp. 2457-2463, 2010.

[27] M. Zanardelli, L. Micheli, L. Cinci, P. Failli, C. Ghelardini, and L. Di Cesare Mannelli, "Oxaliplatin neurotoxicity involves 
peroxisome alterations. PPAR $\gamma$ agonism as preventive pharmacological approach," PLoS ONE, vol. 9, no. 7, Article ID e102758, 2014.

[28] S. S. Jacobs, E. Fox, C. Dennie, L. B. Morgan, C. L. McCully, and F. M. Balis, "Plasma and cerebrospinal fluid pharmacokinetics of intravenous oxaliplatin, cisplatin, and carboplatin in nonhuman primates," Clinical Cancer Research, vol. 11, no. 4, pp. 16691674, 2005.

[29] S. S. Jacobs, C. L. McCully, R. F. Murphy, J. Bacher, F. M. Balis, and E. Fox, "Extracellular fluid concentrations of cisplatin, carboplatin, and oxaliplatin in brain, muscle, and blood measured using microdialysis in nonhuman primates," Cancer Chemotherapy and Pharmacology, vol. 65, no. 5, pp. 817-824, 2010.

[30] O. Elekes, K. Venema, F. Postema, R. Dringen, B. Hamprecht, and J. Korf, "Evidence that stress activates glial lactate formation in vivo assessed with rat hippocampus lactography," Neuroscience Letters, vol. 208, no. 1, pp. 69-72, 1996.

[31] S. Chen, E. A. Oyarzabal, Y. Sung et al., "Microglial regulation of immunological and neuroprotective functions of astroglia," Glia, vol. 63, no. 1, pp. 118-131, 2015.

[32] H. Kajihara, E. Tsutsumi, A. Kinoshita, J. Nakano, K. Takagi, and S. Takeo, "Activated astrocytes with glycogen accumulation in ischemic penumbra during the early stage of brain infarction: immunohistochemical and electron microscopic studies," Brain Research, vol. 909, no. 1-2, pp. 92-101, 2001.

[33] J. R. Goss, M. E. O’Malley, L. Zou, S. D. Styren, P. M. Kochanek, and S. T. Dekosky, "Astrocytes are the major source of nerve growth factor upregulation following traumatic brain injury in the rat," Experimental Neurology, vol. 149, no. 2, pp. 301-309, 1998.

[34] N. E. Chorna, L. I. Santiago-Pérez, L. Erb et al., "P2Y2 receptors activate neuroprotective mechanisms in astrocytic cells," Journal of Neurochemistry, vol. 91, no. 1, pp. 119-132, 2004.

[35] E. Hansson, H. Muyderman, J. Leonova et al., "Astroglia and glutamate in physiology and pathology: aspects on glutamate transport, glutamate-induced cell swelling and gap-junction communication," Neurochemistry International, vol. 37, no. 2-3, pp. 317-329, 2000.

[36] R. Dringen, "Metabolism and functions of glutathione in brain," Progress in Neurobiology, vol. 62, no. 6, pp. 649-671, 2000.

[37] M. E. Gegg, B. Beltran, S. Salas-Pino et al., "Differential effect of nitric oxide on glutathione metabolism and mitochondrial function in astrocytes and neurones: implications for neuroprotection/neurodegeneration?" Journal of Neurochemistry, vol. 86, no. 1, pp. 228-237, 2003.

[38] T. Nakase, G. Söhl, M. Theis, K. Willecke, and C. C. G. Naus, "Increased apoptosis and inflammation after focal brain ischemia in mice lacking connexin43 in astrocytes," American Journal of Pathology, vol. 164, no. 6, pp. 2067-2075, 2004.

[39] Y. S. Gwak, J. Kang, G. C. Unabia, and C. E. Hulsebosch, "Spatial and temporal activation of spinal glial cells: role of gliopathy in central neuropathic pain following spinal cord injury in rats," Experimental Neurology, vol. 234, no. 2, pp. 362-372, 2012.

[40] P. Mamczur, B. Borsuk, J. Paszko et al., "Astrocyte-neuron crosstalk regulates the expression and subcellular localization of carbohydrate metabolism enzymes," Glia, vol. 63, no. 2, pp. 328-340, 2015.

[41] S. Kaneko, T. Maeda, T. Kume et al., "Nicotine protects cultured cortical neurons against glutamate-induced cytotoxicity via alpha7-neuronal receptors and neuronal CNS receptors," Brain Research, vol. 765, no. 1, pp. 135-140, 1997.
[42] A. Pacini, L. di Cesare Mannelli, L. Bonaccini, S. Ronzoni, A. Bartolini, and C. Ghelardini, "Protective effect of alpha7 nAChR: behavioural and morphological features on neuropathy," Pain, vol. 150, no. 3, pp. 542-549, 2010.

[43] M. Bencherif, S. Narla, and M. Stachowiak, "Alpha7 neuronal nicotinic receptor: a pluripotent target for diseases of the central nervous system," CNS \& Neurological Disorders: Drug Targets, vol. 13, no. 5, pp. 836-845, 2014.

[44] S. Shaw, M. Bencherif, and M. B. Marrero, "Janus kinase 2, an early target of $\alpha 7$ nicotinic acetylcholine receptor-mediated neuroprotection against A $\beta$-(1-42) amyloid," The Journal of Biological Chemistry, vol. 277, no. 47, pp. 44920-44924, 2002.

[45] J. Kawamata and S. Shimohama, "Stimulating nicotinic receptors trigger multiple pathways attenuating cytotoxicity in models of Alzheimer's and Parkinson's diseases," Journal of Alzheimer's Disease, vol. 24, supplement 2, pp. 95-109, 2011.

[46] T. Suzuki, I. Hide, A. Matsubara et al., "Microglial $\alpha 7$ nicotinic acetylcholine receptors drive a phospholipase C/IP3 pathway and modulate the cell activation toward a neuroprotective role," Journal of Neuroscience Research, vol. 83, no. 8, pp. 1461-1470, 2006.

[47] Y. Liu, X. Zeng, Y. Hui et al., "Activation of $\alpha 7$ nicotinic acetylcholine receptors protects astrocytes against oxidative stress-induced apoptosis: implications for Parkinson's disease," Neuropharmacology, vol. 91, pp. 87-96, 2015.

[48] J. Massagué, S. W. Blain, and R. S. Lo, "TGF $\beta$ signaling in growth control, cancer, and heritable disorders," Cell, vol. 103, no. 2, pp. 295-309, 2000.

[49] Y. Zhu, B. Ahlemeyer, E. Bauerbach, and J. Krieglstein, “TGFbetal inhibits caspase- 3 activation and neuronal apoptosis in rat hippocampal cultures," Neurochemistry International, vol. 38, no. 3, pp. 227-235, 2001.

[50] K. M. Dhandapani, M. Hadman, L. de Sevilla, M. F. Wade, V. B. Mahesh, and D. W. Brann, "Astrocyte protection of neurons: role of transforming growth factor- $\beta$ signaling via a c-Jun-AP1 protective pathway," The Journal of Biological Chemistry, vol. 278, no. 44, pp. 43329-43339, 2003.

[51] S. M. Wahl, "Transforming growth factor beta (TGF- $\beta$ ) in inflammation: a cause and a cure," Journal of Clinical Immunology, vol. 12, no. 2, pp. 61-74, 1992.

[52] K. C. Flanders, R. F. Ren, and C. F. Lippa, "Transforming growth factor-betas in neurodegenerative disease," Progress in Neurobiology, vol. 54, no. 1, pp. 71-85, 1998.

[53] A. Schober, R. Hertel, U. Arumäe et al., "Glial cell line-derived neurotrophic factor rescues target-deprived sympathetic spinal cord neurons but requires transforming growth factor-beta as cofactor in vivo," Journal of Neuroscience, vol. 19, no. 6, pp. 20082015, 1999.

[54] N.-F. Chen, S.-Y. Huang, W.-F. Chen et al., “TGF- $\beta 1$ attenuates spinal neuroinflammation and the excitatory amino acid system in rats with neuropathic pain," Journal of Pain, vol. 14, no. 12, pp. 1671-1685, 2013.

[55] S. Echeverry, X. Q. Shi, A. Haw, H. Liu, Z.-W. Zhang, and J. Zhang, "Transforming growth factor-betal impairs neuropathic pain through pleiotropic effects," Molecular Pain, vol. 5, article $16,2009$.

[56] J. J. Letterio and A. B. Roberts, "TGF- $\beta$ : a critical modulator of immune cell function," Clinical Immunology and Immunopathology, vol. 84, no. 3, pp. 244-250, 1997.

[57] J. M. Rubio-Perez and J. M. Morillas-Ruiz, "A review: inflammatory process in Alzheimer's disease, role of cytokines," The 
Scientific World Journal, vol. 2012, Article ID 756357, 15 pages, 2012.

[58] T. Gillessen, S. L. Budd, and S. A. Lipton, "Excitatory amino acid neurotoxicity," Advances in Experimental Medicine and Biology, vol. 513, pp. 3-40, 2002.

[59] E.-S. Y. Lee, M. Sidoryk, H. Jiang, Z. Yin, and M. Aschner, "Estrogen and tamoxifen reverse manganese-induced glutamate transporter impairment in astrocytes," Journal of Neurochemistry, vol. 110, no. 2, pp. 530-544, 2009.

[60] R. J. Bridges and C. S. Esslinger, "The excitatory amino acid transporters: pharmacological insights on substrate and inhibitor specificity of the EAAT subtypes," Pharmacology \& Therapeutics, vol. 107, no. 3, pp. 271-285, 2005.

[61] S. Bröer and N. Brookes, "Transfer of glutamine between astrocytes and neurons," Journal of Neurochemistry, vol. 77, no. 3, pp. 705-719, 2001.

[62] D. W. Choi, M. Maulucci-Gedde, and A. R. Kriegstein, "Glutamate neurotoxicity in cortical cell culture," Journal of Neuroscience, vol. 7, no. 2, pp. 357-368, 1987.

[63] I. Shaked, I. Ben-Dror, and L. Vardimon, "Glutamine synthetase enhances the clearance of extracellular glutamate by the neural retina," Journal of Neurochemistry, vol. 83, no. 3, pp. 574-580, 2002.

[64] P. T. Ohara, J.-P. Vit, A. Bhargava et al., "Gliopathic pain: when satellite glial cells go bad," Neuroscientist, vol. 15, no. 5, pp. 450463, 2009.

[65] E. D. Muse, H. Jurevics, A. D. Toews, G. K. Matsushima, and P. Morell, "Parameters related to lipid metabolism as markers of myelination in mouse brain," Journal of Neurochemistry, vol. 76, no. 1, pp. 77-86, 2001.

[66] J. Zou, Y.-X. Wang, F.-F. Dou et al., "Glutamine synthetase down-regulation reduces astrocyte protection against glutamate excitotoxicity to neurons," Neurochemistry International, vol. 56, no. 4, pp. 577-584, 2010.

[67] L. Hertz and T. B. Rodrigues, "Astrocytic-neuronal astrocytic pathway selection for formation and degradation of glutamate/GABA," Frontiers in Endocrinology, vol. 5, p. 42, 2014. 

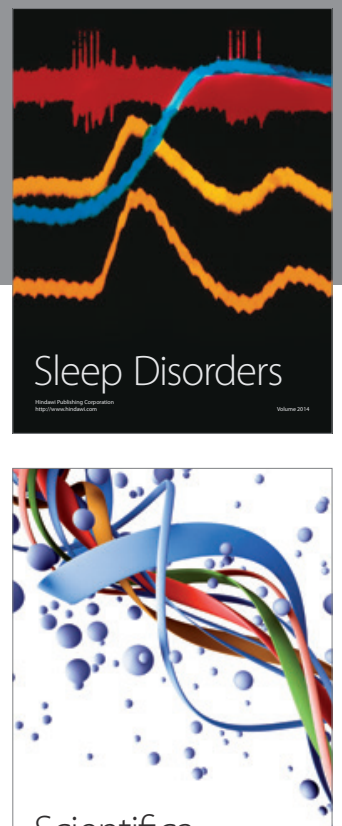

Scientifica
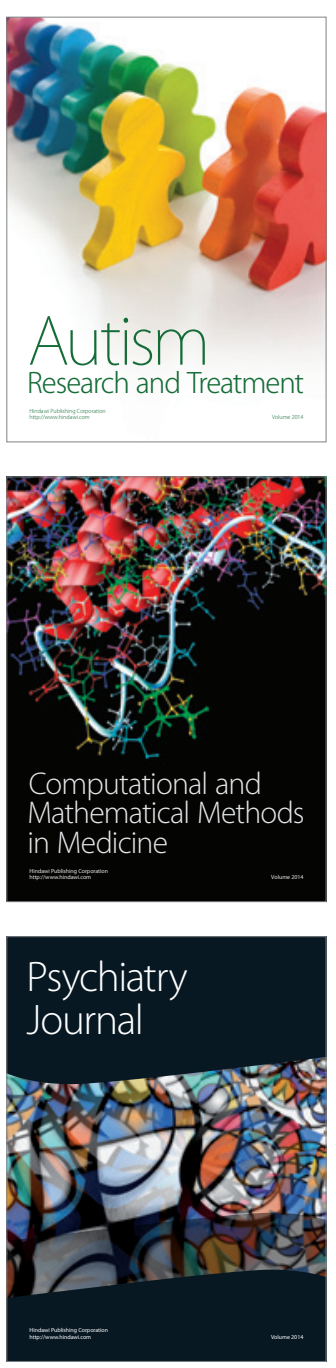
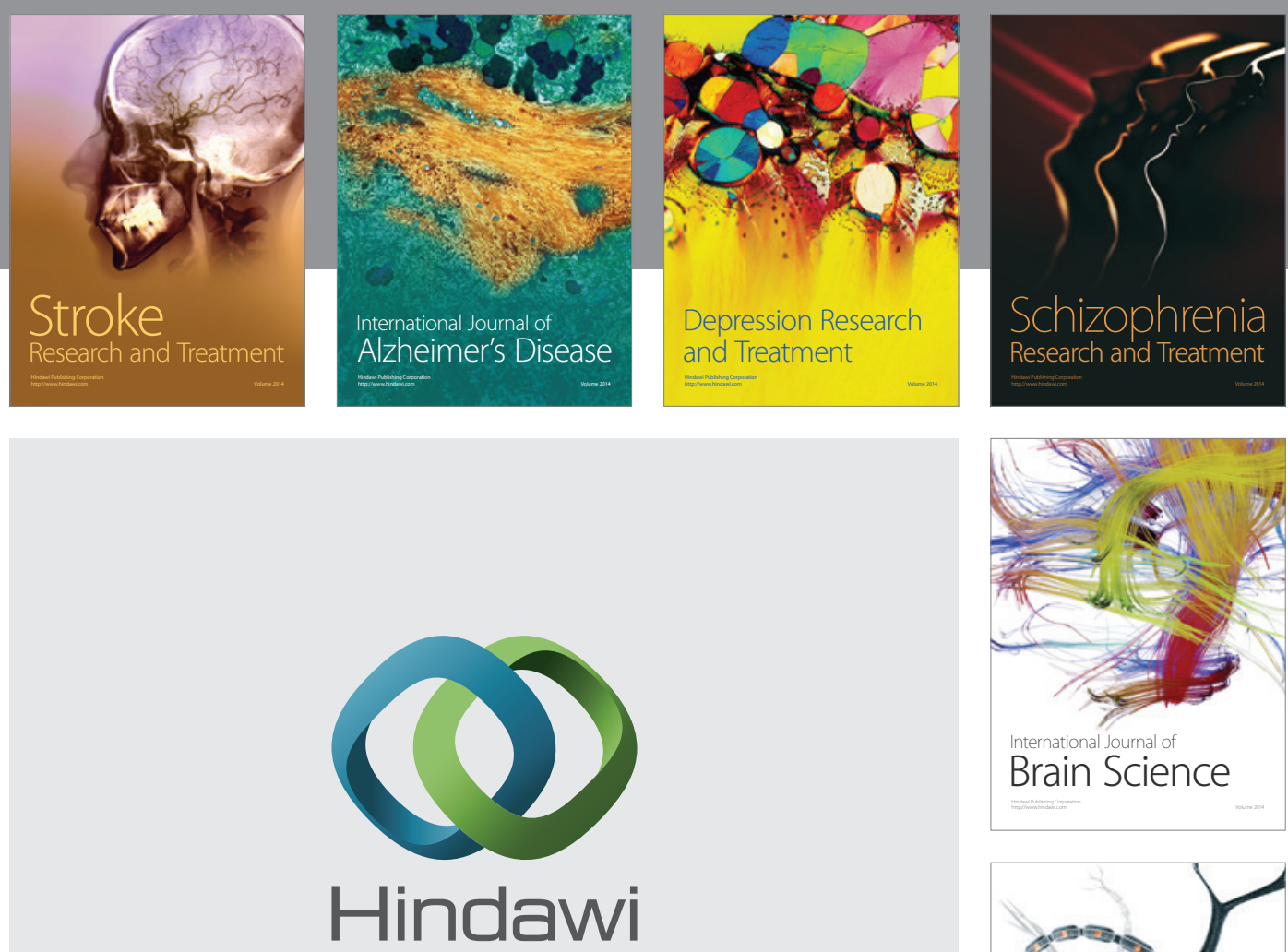

Submit your manuscripts at

http://www.hindawi.com
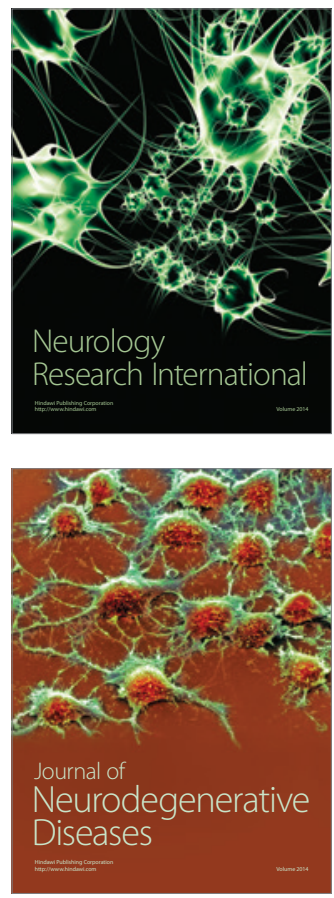

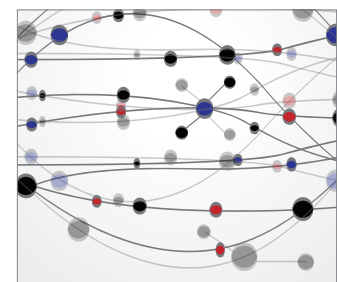

The Scientific World Journal
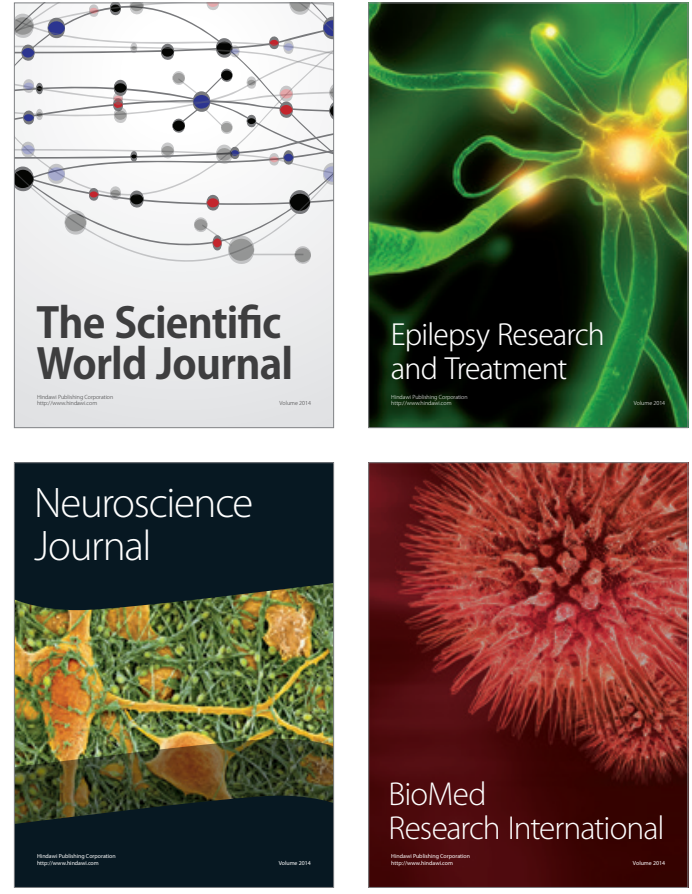

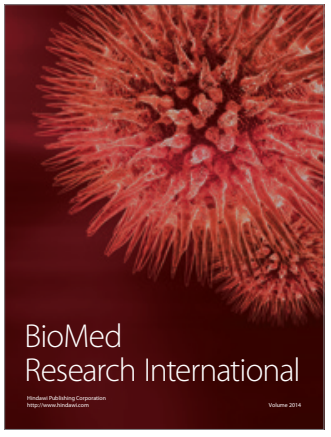

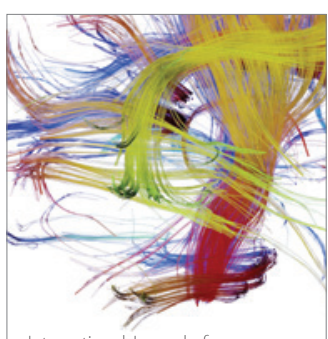

Brain Science

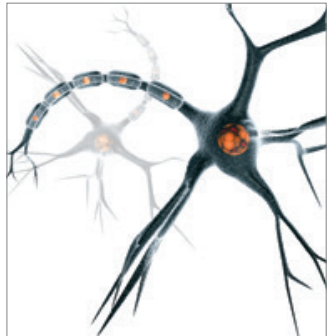

Neural Plasticity
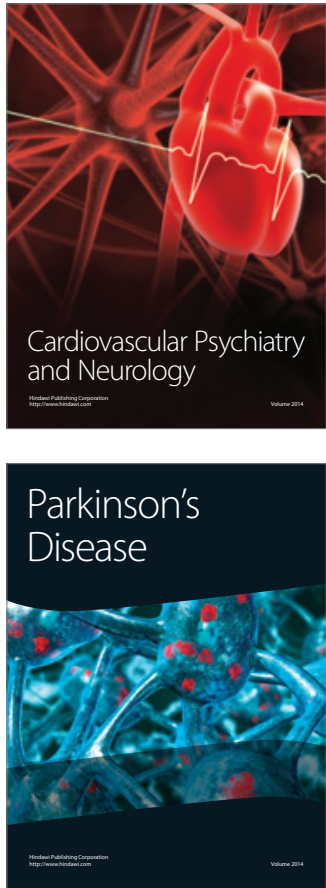